\title{
Secular variation on the territory of the Czech Republic and reduction of the magnetic survey to the epoch 2010.5
}

\author{
Pavel Hejda ${ }^{\star}$, Josef Horáček, Tomáš Bayer
}

Institute of Geophysics of the ASCR, Prague, Czech Republic

\author{
Article history \\ Received October 14, 2011; accepted December 19, 2011. \\ Subject classification: \\ Geomagnetic field variations and reversals, Global and regional models, Magnetic anomalies, Data processing.
}

\begin{abstract}
A recent stage of the magnetic surveying activities in the Czech Republic was started in the fifties by setting up a basic network of the first order. It consists of 199 points. Complete measurements of three components, D, H, and Z, were carried out in 1976-78 and 1994-96. Since 1970 six selected points have been revisited approximately every two years. Five of them are situated close to the Czech boundaries, the last one inland. The repeat station network was complemented by another inland station in 2003. The repeat station measurements, together with the data from neighboring observatories, were now used to reduce the data from the last magnetic survey to the epoch 2010.5 and new magnetic charts were drawn. The accuracy of the results and their comparison with IGRF model is also discussed.
\end{abstract}

\section{Introduction}

The first magnetic survey on Czech territory was carried out by K. Kreil in 1843-1845. He measured the declination, inclination and horizontal intensity at 24 sites (including the Prague Observatory) in Bohemia and derived magnetic maps for 1845 [Kreil and Fritsch 1846]. J. Liznar carried out magnetic measurements between 1889 and 1894 as part of the magnetic mapping of the former Austro-Hungary and created an extensive set of maps for the epoch 1890.0 [Liznar 1898]. During the next 60 years, only measurements of magnetic declination were made.

The recent stage of the magnetic surveying activities was started in the fifties by setting up a basic network of the first order. It consists of 199 points, which have been stabilized by means of granite boundary stones and marked by black and white aluminum rods.

Measurements of the vertical and horizontal components were carried out in 1957-58 and supplemented by reduced values of declination obtained during a former campaign [Bouška et al. 1960]. The network was re-occupied in 1976-78 when three components, D (measured by Matting \& Wiesenberg theodolite), H (by QHM) and Z (by BMZ) were complemented by measurements of the total field $\mathrm{F}$ (by PPM). The latter enabled to correct random errors. The azimuth was determined by observations of the Sun [Bucha et al. 1983]. The last magnetic survey in 1994-96 was carried out by a fluxgate theodolite and a proton precession magnetometer [Hejda et al. 1999]. The magnetic maps of D, H and $Z$ are shown in Figure 1. While the measurements were being made, a revision of the network was undertaken. More than fifty points were found disturbed by building activities and had to be moved to elsewhere.

Since 1970 six selected points have been revisited approximately every two years. Five of them are situated close to the Czech boundary, the last one is in eastern Bohemia. The repeat station network was complemented by station Mýto (western Bohemia) in 2003. The stations, together with neighboring observatories, are shown in Figure 2.

Eight series of measurements are carried out at every station. All measurements are reduced to annual means centered to the middle of the year, in which the station was measured using data from the geomagnetic observatory of Budkov. No on-site variometer is used. The measurements were usually carried out in odd years. According to the recommendation of the first Workshop on European Repeat Station Measurements held in Niemegk in 2003, the term was changed to even years, starting from 2004.

Carrying out the magnetic survey in the first-order network is laborious and expensive. But in fact the local structure of the geomagnetic field is nearly time-invariable. It thus makes sense to update the results of the magnetic survey by means of repeat station measurements.

\section{Temporal behavior of the geomagnetic field}

Figure 3 shows the time variation of the geomagnetic field on Czech territory observed at the repeat stations during the past 40 years. The study of the secular variation is extremely sensitive to any move of the repeat station position. We were happy that all stations have kept their positions for the last thirty years. 
HEJDA ET AL.
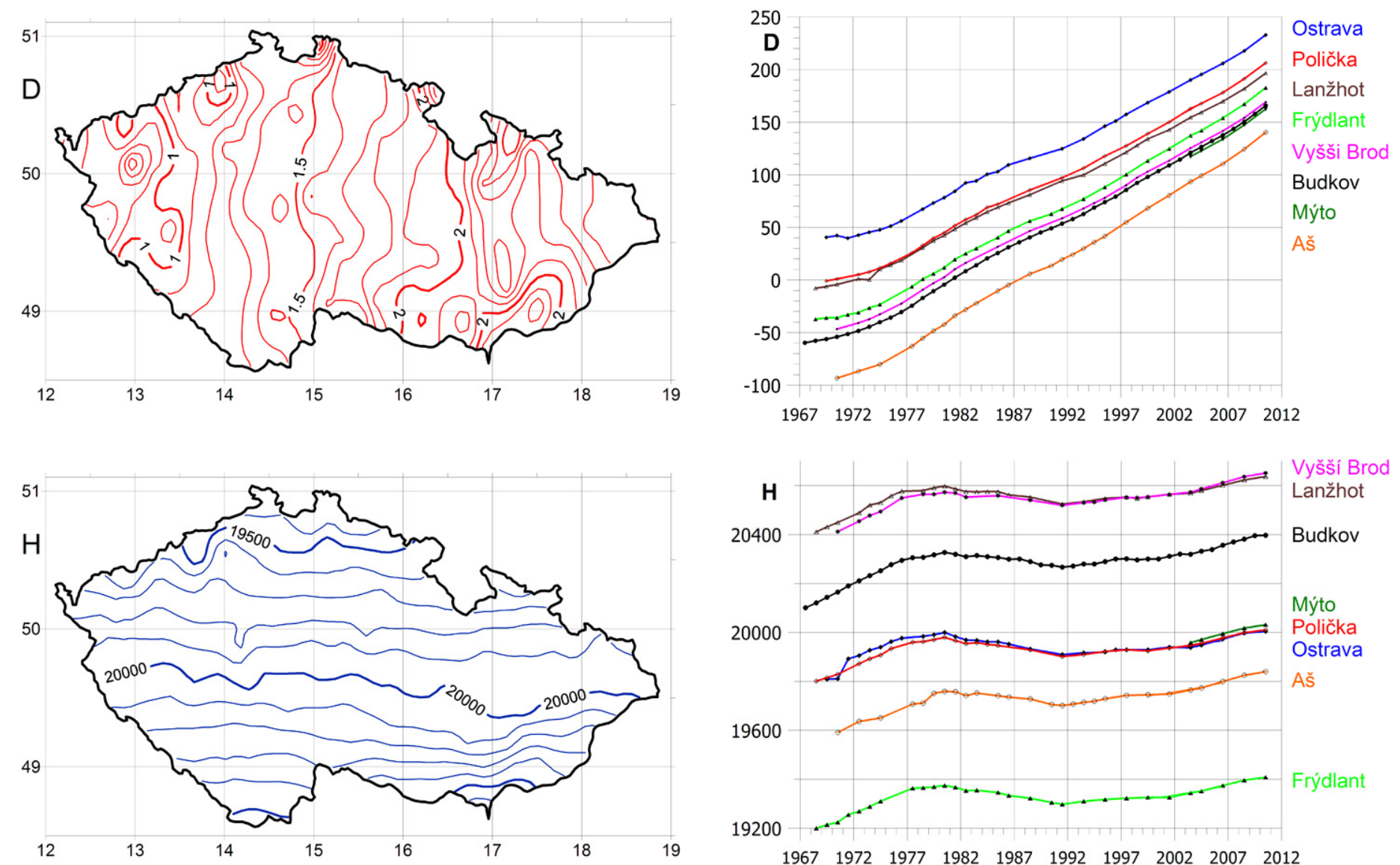

$\begin{array}{llllllllll}1967 & 1972 & 1977 & 1982 & 1987 & 1992 & 1997 & 2002 & 2007 & 2012\end{array}$
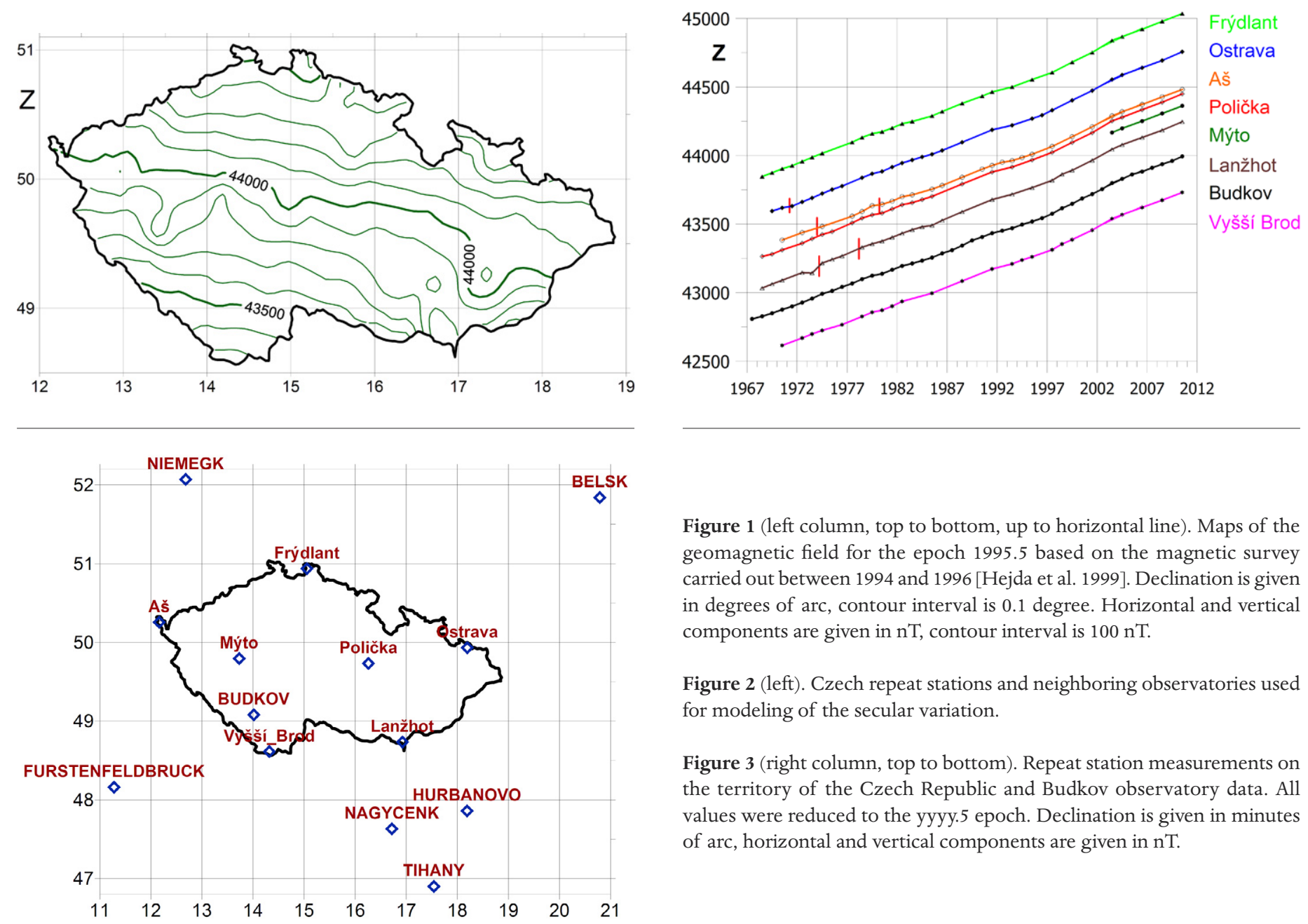

Figure 1 (left column, top to bottom, up to horizontal line). Maps of the geomagnetic field for the epoch 1995.5 based on the magnetic survey carried out between 1994 and 1996 [Hejda et al. 1999]. Declination is given in degrees of arc, contour interval is 0.1 degree. Horizontal and vertical components are given in $\mathrm{nT}$, contour interval is $100 \mathrm{nT}$.

Figure 2 (left). Czech repeat stations and neighboring observatories used for modeling of the secular variation.

Figure 3 (right column, top to bottom). Repeat station measurements on the territory of the Czech Republic and Budkov observatory data. All values were reduced to the yyyy. 5 epoch. Declination is given in minutes of arc, horizontal and vertical components are given in $\mathrm{nT}$. 
Magnetic declination has been increasing during the entire period, and the increment was larger in the west. The temporal change is nearly linear over the last 20 years. During this period, which we are interested in, the secular variation in the east (Ostrava) was 5.8 minutes of arc per year whereas in the west (Aš) 6.6 minutes of arc per year.

The horizontal component has been oscillating with the local maximum around 1980 and local minimum around 1990. Recent observatory data indicates that the horizontal component in central Europe is approaching another local maximum. For example, the yearly mean values of $\mathrm{H}$ in Niemegk were $18,854 \mathrm{nT}$ in $2008,18,866 \mathrm{nT}$ in 2009 and $18,866 \mathrm{nT}$ in 2010, the values for Fürstfeldbruck were 20,929, 20,945 and 20,948, for Budkov 20,381, 20,395 and 20,396 and for Tihany 21,516, 21,528 and 21,528, respectively. This could lead to larger regional differences.

The vertical component behaves most regularly. It has been increasing linearly with very weak regional differences. The secular variation varies between $31.3 \mathrm{nT}$ per year in Vyšší Brod and $32.5 \mathrm{nT}$ per year in Ostrava.

\section{Model of the secular variation}

In order to reduce the magnetic maps to the epoch 2010.5, the secular variation between 1995.5 and 2010.5 had to be computed. In view of the low number of data, we have considered quadratic polynomials computed by the least-squares method. Our original idea was to employ also data from neighboring observatories. There are two good reasons for this step. First, we would increase the number of experimental points and, second, we would avoid unnatural curvature of the contour lines at the edge of the region covered by the data. We started with the complete quadratic polynomial (6 coefficients) and eliminated step-wise the quadratic coefficients. The results indicated that the quadratic terms could introduce artificial effects and, after analyzing the situation, we decided in favour of linear approximation. At that moment there was no reason for keeping the data from neighbouring observatories. Eight measured points are sufficient for a linear 2-dimensional function, and problems at the boundary cannot occur. On the contrary, the linear model fits small areas better. It is
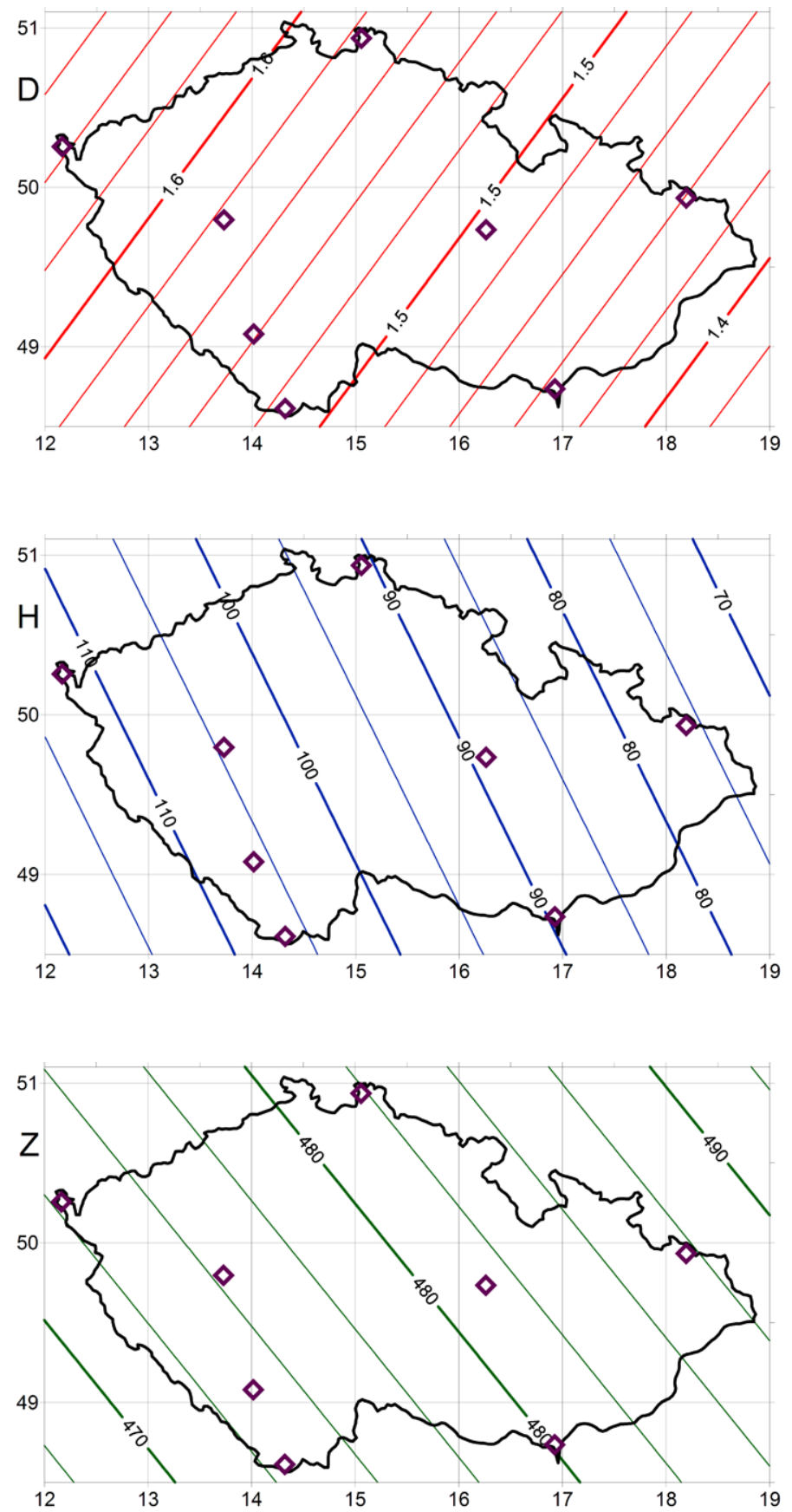

Figure 4. Linear model of secular variation between 1995.5 and 2010.5.

Table 1 (below). Secular variation between 1995.5 and 2010.5 epochs and its linear model; error = observed_value - modeled_value.

\begin{tabular}{|c|c|c|c|c|c|c|}
\hline \multirow[t]{2}{*}{ Station name } & \multicolumn{2}{|c|}{ D (degrees of arc) } & \multicolumn{2}{|c|}{$\mathbf{H}(\mathbf{n} \mathbf{T})$} & \multicolumn{2}{|c|}{$\mathbf{Z}(\mathbf{n} \mathbf{T})$} \\
\hline & observed & error & observed & error & observed & error \\
\hline BUDKOV & 1.5328 & -0.0086 & 107.50 & 1.40 & 474.20 & 0.42 \\
\hline Aš & 1.6475 & 0.0046 & 111.10 & -1.00 & 473.60 & 0.82 \\
\hline Frýdlant & 1.5762 & 0.0006 & 91.30 & 0.51 & 481.45 & -0.89 \\
\hline Lanžhot & 1.4320 & -0.0043 & 88.50 & -1.06 & 480.70 & 0.58 \\
\hline Mýto & 1.5633 & -0.0131 & 102.81 & -1.68 & 472.86 & -2.45 \\
\hline Ostrava & 1.4467 & 0.0073 & 84.20 & 8.27 & 488.00 & 0.82 \\
\hline Poli ka & 1.4740 & -0.0197 & 87.74 & -1.22 & 482.60 & 1.00 \\
\hline Vyšší Brod & 1.5158 & 0.0011 & 109.60 & 3.17 & 469.44 & -3.62 \\
\hline
\end{tabular}



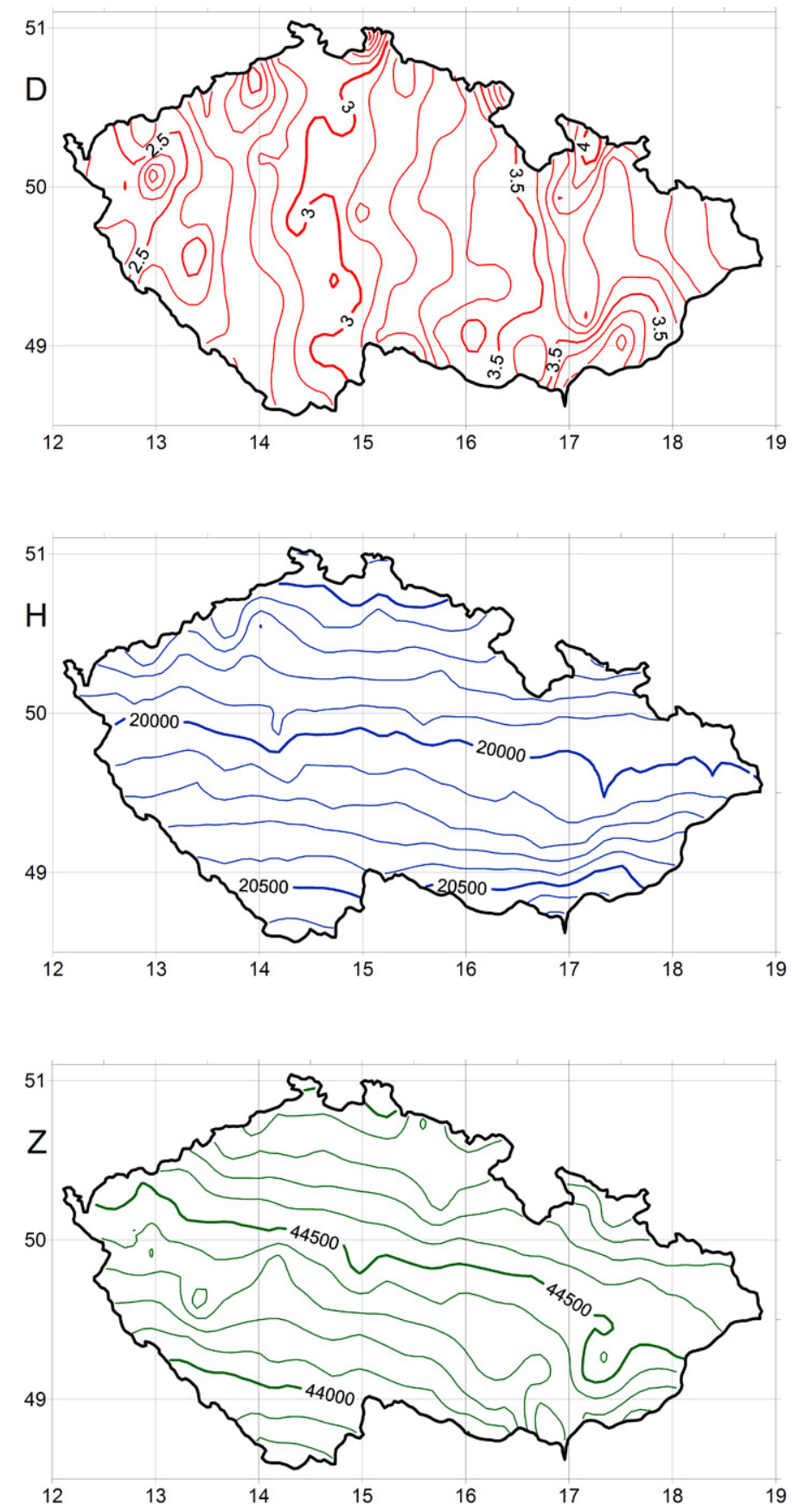

Figure 5. Maps of the geomagnetic field for the epoch 2010.5 derived from the magnetic survey carried out between 1994 and 1996 [Hejda et al. 1999] and linear model of secular variation between 1995.5 and 2010.5. Declination is given in degrees of arc, contour interval is 0.1 degree. Horizontal and vertical components are given in $\mathrm{nT}$, contour interval is $100 \mathrm{nT}$.

advantageous that our repeat stations are situated close to boundaries, because interpolation is more accurate than extrapolation. The linear models of the $D, H$ and $Z$ components of the secular variation are the following: $\mathrm{D}_{\mathrm{SV}}(\lambda, \theta)=$ $0.20788+0.031817 \lambda+0.036256 \theta, \mathrm{H}_{\mathrm{SV}}(\lambda, \theta)=426.78-$ $6.251 \lambda-4.749 \theta, Z_{\mathrm{SV}}(\lambda, \theta)=281.73+2.5578 \lambda+3.182 \theta$, where $\lambda$ denotes longitude and $\theta$ latitude. The maps are shown in Figure 4. The measured values and differences as compared to the model are summed up in Table 1. The results for the declination and vertical component are fairly satisfactory. The maximum error is about 1 per cent $(1.4$ minutes of arc) for the declination and less than 1 per cent for the vertical component. As we have seen already in Section 2, the horizontal component behaves more irregularly. Stations Ostrava and Vyšší Brod are especially anomalous, and the error was not improved even by quadratic approximation. In spite of this, the model of the secular variation provides a good basis for upgrading the maps.

\section{Magnetic maps for the epoch 2010.5}

Values updated to the epoch 2010.5 were computed by the simple formula

$$
\mathrm{D}_{2010.5}(\lambda, \theta)=\mathrm{D}_{1995.5}(\lambda, \theta)+D_{S V}(\lambda, \theta) .
$$

The maps (Figure 5) were drawn with the commercial contouring program Surfer. The contour lines of the declination are relatively smooth in the central part of the Czech Republic, whereas regional anomalies can be found in the western part of the Bohemian Massif and where the Bohemian Massif touches the Carpathians. The horizontal and vertical components confirm the previous statement, even if the regional anomalies in the horizontal component are not so striking.

\section{Discussion}

Upgrading data from the magnetic survey by using repeat station measurements is an efficient and relatively inexpensive way of keeping magnetic maps up-to-date.

An alternative way would be to use the International Geomagnetic Reference Field (IGRF) [Finlay et al. 2010]. Although the IGRF is in general not suitable for approximating a reference field on such small areas as the Czech Republic (characteristic minimum wavelength associated with the IGRF is $3000 \mathrm{~km}$ ), it was shown [Hejda et al. 1999] that the IGRF approximates the measured magnetic field on Czech territory surprisingly well. The results summed up in Table 2 confirm this statement. If we realize that the differences between the observed and modeled data are in some areas as much as hundreds of nanoteslas, the results in Table 2 provide a very good fit. Nonetheless, the IGRF model of the secular variation is unbalanced. All differences between the model and measured data are positive for the declination and negative for the horizontal and vertical components. Anyway, the fit obtained by the linear model based on repeat station measurements is one order more accurate and should be given priority. It confirms that the repeat station surveys represent an important element in the chain of geomagnetic field observations.

Our results are in a good agreement with other regional studies [e.g. Chen et al. 2010 or Qamili et al. 2010], which came to the conclusions that whereas long-term trends in secular variation are consistent with IGRF better fit of regional anomalies require models based on local data . 


\begin{tabular}{|c|c|c|c|c|c|c|}
\hline \multirow[t]{2}{*}{ Station name } & \multicolumn{2}{|c|}{$\mathrm{D}$ (degrees of arc) } & \multicolumn{2}{|c|}{$\mathbf{H}(\mathbf{n T})$} & \multicolumn{2}{|c|}{$\mathrm{Z}(\mathbf{n T})$} \\
\hline & IGRF & diff & IGRF & diff & IGRF & diff \\
\hline BUDKOV & 1.5058 & 0.0270 & 112.05 & -4.55 & 484.22 & -10.02 \\
\hline Aš & 1.6314 & 0.0161 & 112.74 & -1.64 & 487.56 & -13.96 \\
\hline Frýdlant & 1.5593 & 0.0169 & 99.64 & -8.34 & 501.21 & -19.76 \\
\hline Lanžhot & 1.3960 & 0.0360 & 102.52 & -14.02 & 484.26 & -3.56 \\
\hline Mýto & 1.5495 & 0.0138 & 109.76 & -6.95 & 489.08 & -16.22 \\
\hline Ostrava & 1.4124 & 0.0343 & 94.58 & -10.38 & 495.79 & -7.79 \\
\hline Poli ka & 1.4604 & 0.0136 & 101.48 & -13.74 & 492.67 & -10.07 \\
\hline Vyšší Brod & 1.4745 & 0.0413 & 112.82 & -3.22 & 481.22 & -11.78 \\
\hline
\end{tabular}

Table 2. Secular variation between 1995.5 and 2010.5 epochs and its linear model; error = observed_value - modeled_value.

More detailed information, including the values of the three magnetic component of all station of the basic network of the first order, reduced to the epoch 2010.5, will be available on the web of the Institute of Geophysics of the ASCR, http://www.ig.cas.cz.

Acknowledgements. The data acquisition was supported by the project of large research infrastructure CzechGeo/EPOS, Grant No. LM2010008.

\section{References}

Bouška J., V. Bucha and A. Kočí (1960). Geomagnetische Karten der Tschechoslowakischen Republik für die Epoche 1958,0, Travaux Inst. Géophys. Acad Tchécosl. Sci., No 112.

Bucha, V., I. Cupal, J. Horáček and A. Pazderková (1983). Investigation of the geomagnetic field and its secular variation on the territory of Bohemia and Moravia: epoch 1978.5, Travaux Inst. Géophys. Acad Tchécosl. Sci., No 583.

Chen, B., Z.W. Gu, J.T. Gao, J.H. Yuan and C.Z. Di (2010). Study of geomagnetic secular variation in China, Chinese J. Geophys., 53, 2144-2154; doi:10.3969/j.issn.0001-5733. 2010.09.014

Finlay, C.C, S. Maus, C.D. Beggan, T.N. Bondar, A. Chambodut, T.A. Chernova, A. Chulliat, V.P. Golovkov, B. Hamilton, M. Hamoudi, R. Holme, G. Hulot, W. Kuang, B. Langlais, V. Lesur, F. J. Lowes, H. Luhr, S. Macmillan, M. Mandea, S. McLean, C. Manoj, M. Menvielle, I. Michaelis, N. Olsen, J. Rauberg, M. Rother, T. J. Sabaka, A. Tangborn, L. Toffner-Clausen, E. Thebault, A.W.P. Thomson, I. Wardinski Z. Wei and T.I. Zvereva (2010). International Geomagnetic Reference Field: the eleventh generation, Geophys. J. Int., 183, 1216-1230; doi: 10.1111/ j.1365-246X.2010.04804.x.

Hejda, P., J. Horáček, V. Bucha and I. Cupal (1999). Geomagnetic field on the territory of the Czech Republic for 1995.5, Phys. chem. Earth (A), 24, 445-448.

Kreil, K., and K. Fritsch (1848). Magnetische und geographische Ortbestimmungen in Böhmen, Erster Jahrgang 1846, Prag.
Liznar, J (1898). Die Vertheilung der erdmagnetischen Kraft in 'Osterreich-Ungarn zur Epoche 1890,0 nach den in den Jahren 1889 bis 1894 ausgeführten Messungen, Teil I., II., Wien.

Qamili, E., A. De Santis, G. Cianchini, B. Duka, L.R. GayaPique, G. Dominici and N. Hyka (2010). Two geomagnetic regional models for Albania and south-east Italy from 1990 to 2010 with prediction to 2012 and comparison with IGRF-11, Earth Planets Space, 62, 833-841; doi: 10.5047/eps.2010.07.011.

\footnotetext{
${ }^{\star}$ Corresponding author: Pavel Hejda, Institute of Geophysics of the ASCR, Prague, Czech Republic; email: ph@ig.cas.cz.

C 2012 by the Istituto Nazionale di Geofisica e Vulcanologia. All rights reserved.
} 